\title{
A instalação e organização da Escola Normal de Goiás (1884)
}

\section{The establishment and organization of the Goiás State Normal School (1884)}

\section{Tarsio Paula dos Santos}

Orcid: https://orcid.org/0000-0001-7448-1001

Universidade Estadual de Goiás, Anápolis, Goiás, Brasil, tarsio_13@hotmail.com

\author{
Sandra Elaine Aires de Abreu \\ Orcid: https://orcid.org/0000-0001-6242-961X \\ Universidade Estadual de Goiás, Anápolis, Goiás, Brasil, \\ sandraeaa@yahoo.com
}

DOI: 10.21680/2596-0113.2021v4nOID25887

Citation: Santos, T. P. dos. \& Abreu, S. E. A. de. (2021). A instalação e organização da Escola Normal de Goiás (1884). History of Education in Latin America - HistELA, 4, e25887.

Competing interests: The authors have declared that no competing interests exist.

Editor: Olivia Morais de Medeiros Neta

Received: 10/07/2021

Approved: 30/07/2021

\section{OPEN ACCESS}

\begin{abstract}
Resumo
O presente trabalho tem como objetivo analisar a criação do educandário de formação de professores normalistas goianos e suas normas regulamentadoras no ano de 1884. Como embasamento teórico, utilizou-se os estudos de Bretas (1991), Canezin \& Loureiro (1994), Hahner (2011), Saviani (2009), Tanuri (2000) e Villela (2000). Para essa investigação, as metodologias adotadas foram a pesquisa bibliográfica e a análise documental. Como resultado, pôde-se entender os trâmites que levaram à instalação da Escola Normal goiana e como esta estava organizada, segundo as prescrições estaduais.
\end{abstract}

Palavras-chave: Escola Normal. Província de Goiás. Regulamento da Escola Normal de Goiás. Período imperial.

\section{Abstract}

The present study is objective is to analyze the constitution of the normalist teachers education and training in Goiás and the school regulations in 1884. As a theoretical basis, was used the studies of Bretas (1991), Canezin \& Loureiro (1994), Hahner (2011), Saviani (2009), Tanuri (2000), and Villela (2000). For this investigation, we adopted two research methods: the bibliographic research and document analysis. As a result, we were able to understand the procedures that led to the foundation of the Goiás State Normal School and how it used to be structured, according to the state's recommendations.

Keywords: Normal School. Province of Goiás. Goiás State Normal School Regulations. Imperial Era. 


\section{Introdução}

No final século XVIII, movido pela preocupação da instrução popular, surgiu na França um educandário específico para a formação de professores primários, as escolas normais (Saviani, 2009). Esse exemplo foi seguido por outros estados nacionais e pelo Império do Brasil.

No Brasil, a partir de 1835, foram criadas as primeiras escolas normais nas províncias do Rio de Janeiro (1835), Minas Gerais (1835), Bahia (1836) e São Paulo (1846) (Villela, 2000). Elas eram exclusivas para rapazes, o currículo era semelhante ao do ensino primário, com poucas variações, o foco era ensinar os normalistas a dominar o método mútuo, sendo que em algumas escolas, considerava-se também o método simultâneo, e as exigências para ingresso no curso normal eram pautadas em questões morais e de bons costumes (Villela, 2000).

Ademais, nas décadas de 1850 e 1860, realizaram-se várias tentativas de abertura de educandários de ensino normal no Brasil, sendo estas ações marcadas por dificuldades como "instabilidade evidenciada através de reformas, extinções, transformações, mudanças de prédios, etc" (Villela, 2000, p. 114-115). Isso pode ser verificado pelo fato de que, em 1867, só haviam 4 (quatro) instituições de ensino normal em atividades nas províncias do Rio de Janeiro, Pernambuco, Bahia e Piauí (Tanuri, 2000).

No final da década de 1870 , tem-se destaque para a Reforma Leôncio de Carvalho, decreto n. 7.247 de 19 de abril de 1879, que incentivou a cooperação entre o governo imperial e as províncias para criação de escolas normais (o que não foi efetivado); abriu-se a possibilidade de aulas mistas, ou seja, homens e mulheres dividindo o mesmo espaço de aprendizagem, para os ensinos primário e normal. Acerca deste último, a referida legislação organizou o curso normal em uma série de cadeiras avulsas de frequência não obrigatória e com exames livres; criação de cursos primários anexos para a prática dos docentes em formação; enriqueceu o currículo (seguindo os ideais positivistas) e ampliou os critérios para ingresso nesse ensino (Saviani, 2009; Tanuri, 2000).

Assim sendo, as ações acima destacadas juntamente com vários outros eventos, tais como a maior disseminação dos ideias positivistas que promoveram uma maior valorização do ensino (Tanuri, 2000), trouxeram um aumento significativo das escolas normais no Brasil e o acesso do sexo feminino nesse nível de instrução, pois, "do total de 22 escolas normais funcionando nas províncias em 1882, 15 eram escolas mistas, enquanto só cinco eram restritas aos homens e duas as mulheres" (Hahner, 2011, p. 471).

Seguindo essas ações, a Província de Goiás em 1884, instalou a primeira Escola Normal goiana na antiga capital, a Cidade de Goiás. Essa criação já havia acontecido anteriormente através de leis (Resolução n. 15, de 28 de julho de 1858, e Resolução n. 676, de 3 de agosto de 1882), contudo não foram efetivadas, devido a inúmeras dificuldades encontradas na província (Bretas, 1991; Canezin \& Loureiro, 1994).

Nestes termos, o presente estudo dedica-se em analisar a criação do educandário de formação de professores normalistas goianos e suas normas regulamentadoras no ano de 1884, tendo em vista que a delimitação temporal se refere ao ano de estabelecimento do Regulamento da Escola Normal de 1884 e a instalação de tal escola na antiga capital goiana, a Cidade de Goiás. Além disso, também se buscou, como objetivos específicos, apontar quais foram as primeiras 
tentativas de criação da Escola Normal em Goiás no século XIX, compreender o processo de instalação da instituição de formação de professores primários em Goiás entre 1839 a 1884 e descrever os parâmetros organizativos da Escola Normal goiana, através do Regulamento de 1884

Para alcançar os objetivos traçados nessa investigação, considerando a abordagem qualitativa, utilizou-se como metodologias a pesquisa bibliográfica e a análise documental. Os principais documentos utilizados foram os relatórios dos presidentes da Província de Goyaz dos anos de 1839, 1849, 1850 e 1851; o Correio Oficial números 17 e 18 do ano de 1884 e o Regulamento da Escola Normal de Goyaz (1884).

\section{A Escola Normal de Goiás: Tentativas de criação e o processo de instalação (1839-1884)}

As primeiras menções da necessidade de uma escola normal na província de Goiás foram realizadas por presidentes locais na primeira metade do século XIX. Esses discursos se apresentaram como via de solução para a falta de preparado dos professores e a precariedade do ensino primário, questões que prejudicavam o progresso social em Goiás (Bretas, 1991; Fleury, 1849; Gomes, 1851; Machado, 1850; Mascarenhas, 1839).

Nesse âmbito, em 1858, através da Resolução n. 15, de 28 de julho, o presidente Gama Cerqueira criou a Escola Normal na Cidade de Goiás (GOYAZ, 1858). Contudo, essa primeira tentativa não prosperou, pois não havia pessoal habilitado para lecionar na instituição, não existia prédio adequado e as dificuldades financeiras impossibilitavam a compra de materiais e manter o funcionamento da escola. Após esse fato, de 1860 a 1880, o que se observou nos discursos políticos acerca do ensino normal não levou a nenhuma atitude concreta (Bretas, 1991; Canezin \& Loureiro, 1994).

Ademais, em novembro de 1881, como resultado da criação da Escola Normal da Corte e das contribuições da Reforma Leôncio de Carvalho, o governo imperial emitiu às províncias a Circular n. 4.465, de 26 de novembro. Dessa atitude tem-se que:

\footnotetext{
[...] o Ministério dos Negócios do Império, [...], solicitou aos presidentes de províncias e às assembleias provinciais que fossem empreendidos esforços no sentido de criar a Escola Normal nas províncias que ainda não haviam tido condições para cria-la de acordo com o plano estabelecido no artigo 9ำ do Decreto № 7.247, de 19 de abril de 1879 (Canezin \& Loureiro, 1994, p. 28).
}

Diante do exposto acima, em Goiás, a partir dos próprios esforços dos cofres públicos e a possibilidade de criação de apenas uma instituição para a formação de professores e professoras, o presidente goiano Cornélio Pereira de Magalhães (18821882) estabeleceu novamente a criação da Escola Normal na Cidade de Goiás em 1882, Resolução n. 672, de 3 de agosto (Bretas, 1991; Canezin \& Loureiro, 1994; Silva, 1975).

A partir dessa legislação, o ensino normal ficou organizado em sistema de aulas mistas, formado por matérias avulsas de frequência não obrigatória, currículo pautado 
nas ciências modernas (physica, chimica, botanica e zoologia) de influência positivista entre outros aspectos. Assim, a organização curricular configurou-se da seguinte forma:

\author{
1ㅡㅡ (primeira) Lingua nacional, litteratura classica portugueza, litteratura pátria. \\ $2^{\underline{a}}$ (segunda) Grammatica, leitura e versão da língua franceza. \\ $3^{a}$ (terceira) Arithmetica até logarithmos exclusive; systema métrico decimal, algebra até \\ equação do $2^{\circ}$ gráo, geometria plana; desenho linear. \\ $4^{\text {a }}$ (quarta) Noções de logica, methodos lógicos de explorar, descobrir, verificar e \\ demonstrar; estudos das regras e processos formaes dos diversos methodos. \\ $5^{\text {a }}$ (quinta) Cosmographia, geographia, chorographia da Provincia de Goyaz; rudimentos \\ da geologia. \\ 6 ${ }^{\text {a }}$ (sexta) Historia do Brazil. \\ $7^{\text {a }}$ (sétima) Rudimentos da physica, chímica, botanica e zoologia. \\ $8^{\text {a }}$ (oitava) Pedagogia (Goyaz, 1882, p. 1).
}

Ademais, aos normalistas diplomados era concedido "direito à vitaliciedade, à inamovibilidade, a escolha das cadeiras ou colocações que mais the conviessem a uma gratificação adicional de $25 \%$ sobre o vencimento" (Canezin \& Loureiro, 1994, p. 28). Todavia, essa legislação não foi efetivada, o que se configurou como a segunda tentativa de criação da referida escola.

Em princípios de 1884, o projeto de criação da Escola Normal goiana de 1882 foi retomado por Camillo Augusto Maria de Brito (1884-1884) e a instalação do educandário foi efetivada, concretizando assim, o desejo goiano surgido em 1839 (Silva, 1975). Para esse fim, foi elaborado um novo Regulamento para o ensino normal: Ato n. 3.474, de 12 de março de 1884, o Regulamento da Escola Normal.

Dessa forma, adotando o sistema de coeducação, a Escola Normal foi fundada na Cidade de Goiás em 21 de abril de 1884, em solenidade com a presença de professores, lideranças políticas e religiosas (Goyaz, 1884a). Apesar dessa instalação, essa escola teve vida efêmera, sendo fechada em 1886, sem formar nenhum professor primário. Dentre os motivos desse fracasso estão críticas ao sistema de aulas mistas, conflitos entre os defensores e alunos do Liceu contra os normalistas, descontinuidade política do projeto para o ensino normal, entre outros (Bretas, 1991; Silva, 1975).

\title{
A organização da Escola Normal de Goiás: Ato n. 3.374, de 12 de março de 1884
}

Durante seu funcionamento entre 1884 e 1886, a Escola Normal de Goiás foi regulada apenas por um documento: Ato n. 3.374 de 12 de março de 1884, Regulamento da Escola Normal de Goiás (Goyaz, 1884b). Esse regulamento era composto por 88 (oitenta e oito) artigos, divididos em 10 (dez) capítulos, que tratavam do ensino normal quanto as aulas, exames, ano letivo, critérios de matrícula, deveres do discentes, matérias escolares, entre outros.

A instituição de formação de professores primários goianos funcionou no prédio do Liceu, nos períodos matutinos e vespertinos (Goyaz, 1884c), organizados pela 
Congregação com aprovação do presidente da província (Art. 7ํㅗㄴ, Regulamento da Escola Normal). Para as práticas dos normalistas haviam dois cursos primários anexos, um masculino e outro feminino (Art. 5․, Regulamento da Escola Normal) e para as cadeiras de ciências experimentais existiam um gabinete de ciências naturais e um laboratório de chimica (Arts. 6o e 39으. Regulamento da Escola Normal). Funcionava também no mesmo espaço uma secretaria, onde o secretário realizava seus trabalhos e uma biblioteca para empréstimos de livros (Arts. 18ㅇ - $\S 4^{\circ}$ e $70^{\circ}$ ).

Acerca do ensino, era ofertado apenas o curso normal composto por 3 (três) anos/séries, sendo que o $1^{\circ}$ ano composto de 5 (cinco) cadeiras, o $2^{\circ}$ ano de 6 (seis) cadeiras e $03^{\circ}$ ano de 5 (cinco), voltado às pessoas destinadas ao magistério (Arts. $1^{\circ}$ e $\left.2^{\circ}\right)$. $O$ documento em questão também indicava saberes complementares de acordo com o sexo do discente: às moças seriam ensinadas trabalhos com agulhas e aos rapazes noções de agricultura, geometria elementar e desenho linear (Art. $3^{\circ}$, Regulamento da Escola Normal). Assim, a distribuição das cadeiras para o ensino normal configurava-se da seguinte maneira:

1ำ (primeiro) ano:1 ${ }^{a}$ cadeira: Língua Nacional, analise gramatical; $2^{\underline{a}}$ cadeira: Aritmética, metrologia; $3^{\mathrm{a}}$ cadeira: Cosmographia, geografia em geral 5 (cinco) partes do mundo e especialmente do Brasil; 4 $4^{\mathrm{a}}$ cadeira: Pedagogia teórica e $5^{\mathrm{a}}$ cadeira: Rudimentos da chimica e da physica; $2^{\circ}$ (segundo) ano: $1^{\underline{a}}$ cadeira: Literatura pátria, analise lógica, leitura de clássicos e exercícios de estilo, $2^{\mathrm{a}}$ cadeira: Língua francesa, gramática, leitura e versão, $3^{a}$ cadeira: História do Brasil até a independência, 4⿳a cadeira: Pedagogia, metodologia e 5 ${ }^{a}$ cadeira: Geometria elementar, desenho linear e 6 ${ }^{a}$ cadeira: Rudimentos da zoologia e botânica; e $3^{\circ}$ (terceiro) ano: $1^{\text {a }}$ cadeira: Aritmética e suas aplicações até logaritmos, álgebra até equações do $2^{-}$grau, $2^{\underline{a}}$ cadeira: Corographia da Província de Goyaz, $3^{\text {a }}$ cadeira: História do Brasil - Império, 4ª cadeira: Noções de geologia, physica, chimica e suas aplicações e $5^{\text {a }}$ cadeira: Noções de lógica, métodos lógicos de explorar, descobrir, verificar e demonstrar; estudos das regras e processos formais dos diversos métodos (Goyaz, 1884b, p. 1).

No que se refere ao tempo escolar, organizou-se da seguinte forma: as aulas da escola ocorriam diariamente de segunda a sábado, nos períodos matutino e vespertino, com duração de 60 (sessenta) minutos cada uma e 120 (cento e vinte) minutos para as aulas práticas no curso primário (GOYAZ, 1884c). O período anual letivo iniciava no dia 15 de março e terminava no dia 15 de novembro (Art. 30ํ, Regulamento da Escola Normal). Os feriados escolares eram aos domingos e dias santos de guarda, os feriados estabelecidos por lei, dias de luto nacional marcados pelo governo, período do carnaval e a semana santa (Art. 43을 Regulamento da Escola Normal). O período de matrículas ocorria durante o dia $1^{\circ}$ a 30 de março (Art. 26으, Regulamento da Escola Normal). Já os exames, davam-se a partir de inscrição, de 1응 de março a 15 de novembro, e de aplicação, dia seguinte do término das aulas e entre

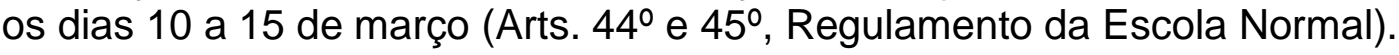

No que tange ao ingresso no ensino normal em Goiás entre 1884 e 1886, para matrícula na escola era necessário solicitar do diretor o requerimento para preencher, anexando a ele documento que comprovasse que o aluno tinha idade mínima exigida, sendo para rapazes era 12 (doze) anos e para as moças 14 (quatorze) anos, atestados de não possuir doenças contagiosas e de boa conduta moral (Art. 23ํㅡ, Regulamento da Escola Normal).

Dessa forma, após a entrega e aprovação da documentação, o candidato era submetido a um exame de matérias que constava de leitura e escrita, das quatro operações aritméticas e de noções de instrução moral e religiosa, sendo realizado perante comissão examinadora formada por professores da instituição (Arts. 24ํㅡ e 
25ํ․ Regulamento da Escola Normal). A aprovação em todo processo garantia a matrícula na Escola Normal goiana e a inscrição no Livro de Matrículas (Arts 26ㅇ). Vale destacar que havia a possibilidade de alunos ouvintes, ou seja, pessoas interessadas em assistir as aulas do curso normal e realizar os exames das disciplinas, mas que não integravam o rol de alunos (Arts. 41 e 44ํㅡ, Regulamento da Escola Normal).

Os alunos da Escola Normal de Goiás deveriam frequentar todas as aulas, haja vista que o acúmulo de faltas justificadas ou não, acarretariam a reprovação do mesmo (Art. 31으, Regulamento da Escola Normal). As aulas eram mistas, contudo, havia separação entre homens e mulheres dentro do espaço de aprendizagem. Para manter a ordem e fiscalizar as aulas, o diretor do educandário deveria estar sempre presente (Arts. $0^{\circ}$ e $41^{\circ}$, Regulamento da Escola Normal). Para as moças era permitido que os pais ou cuidadoras assistissem as aulas, conquanto que mantivessem a urbanidade (Art. 42을 Regulamento da Escola Normal).

A respeito da conduta e disciplina dos normalistas, verifica-se que estes deveriam atender as normas de boa conduta, pois a irregularidade levaria à expulsão. As penalidades eram divididas em dois tipos: as reservadas e as públicas, cabendo serem decididas pela Congregação da escola, contudo, poder-se-ia recorrer ao presidente da província (Arts. $33^{\circ}$ e $34^{\circ}$, Regulamento da Escola Normal).

O quadro de professores formou-se a partir dos docentes em exercício no Liceu e para as novas cadeiras de ciências experimentais foram realizadas nomeações (Art. 4ํㅡ, Regulamento de Escola Normal). Esses profissionais tinham as incumbências de lecionar acerca dos saberes das disciplinas, manter a ordem e disciplina durante as aulas, observar o progresso dos alunos, anotar as faltas e acatar as decisões da

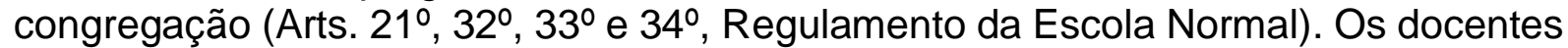
também eram submetidos a penalidades pela quebra de alguma ordenança do referido documento, o que acarretaria em multas descontadas de seus vencimentos (Arts. $77^{\circ}$ e $78^{\circ}$ ).

Outrossim, o processo avaliativo do curso normal em questão era dividido em exames orais, teóricos e práticos. Para os orais, os temas eram sorteados no momento da aplicação e os teóricos eram referentes a todo o programa de ensino

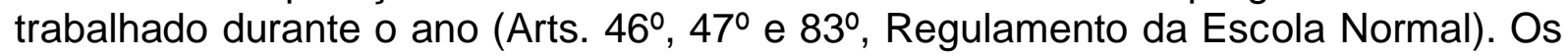
resultados consistiam em notas com as seguintes classificações: aprovação simples, plena e com distinção (Art. 47º, Regulamento da Escola Normal).

Aos que concluíam o curso normal, dava-se o direito ao diploma de normalista. Essa diplomação permitia a nomeação em qualquer cadeira de ensino primário, sendo esta vitalícia, a dispensa em concurso públicos para vagas de instrução primária e $25 \%$ a mais nos vencimentos. Além disso, os professores formados na referida instituição poderiam conseguir licença para lecionar alguma matéria na Escola Normal

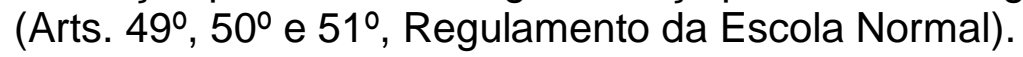

Dessa forma, a Escola Normal de Goiás, na primeira tentativa de instalação, ficou organizada até que, em 1886, foi fechada e criada uma cadeira de Pedagogia, anexa ao Liceu, para formar professores. Essa cadeira não chegou a formar nenhum professor, sendo fechada ao final do ano de sua criação e reestabelecida em 1888 (Canezin \& Loureiro, 1994). 


\section{Considerações finais}

As escolas normais foram criadas no Brasil a partir da primeira metade do século XIX. Contudo, pela falta de um sistema nacional educacional em decorrência do Ato Adicional de 1834, as províncias não gozavam de recursos para o sucesso da formação de seus quadros docentes em suas próprias escolas normais, haja vista que as mesmas se encontravam em dificuldades, tais como a falta de recursos financeiros, pessoal habilitado para o ensino normal, prédio adequado entre outros (Tanuri, 2000).

Ademais, Villela (2000) destaca que as instituições de formação de professores normalistas no Brasil só alcançaram instabilidade a partir do final da década de 1860, quando vários fatores sociais, culturais, ideológicos e políticos conduziram a revalorização das escolas normais.

Nesse âmbito, pode-se identificar em Goiás duas tentativas iniciais para criação da Escola Normal na Província, a partir da Resolução n. 15, 28 de julho de 1858 e a Resolução n. 676, de 3 de agosto de 1882. Todavia, acerca da primeira investida de criação em 1858, as dificuldades financeiras, a falta de professores habilitados e prédio adequado não favoreceram essa ação. Já, sobre a segunda investida de criar a Escola Normal goiana, a oposição ao sistema de aulas mista e a proposta de utilizar o prédio do Liceu para a referida instituição levaram as autoridades a ficarem omissas diante desse projeto (Bretas, 1991; Canezin \& Loureiro, 1994).

Ademais, a instalação da Escola Normal de Goiás ocorreu de fato em 1884, seguindo o projeto de 1882. Através do Ato n. 3.374, o ensino normal em Goiás foi organizado em um curso normal de 3 (três) anos de duração com aulas mistas, criação de dois cursos primários, sendo um masculino e outro feminino, para prática docente dos normalistas, currículo dividido em cadeiras com o foco nas ciências modernas de influência positivista entre outros aspectos. Aos diplomados eram concedidas regalias como dispensa submissão em concursos público para vagas no quadro de professores primários, aumento de $25 \%$ nos vencimentos, vitaliciedade no cargo de docente primário público e possibilidade de lecionar no ensino normal (Goyaz, 1884b).

Em suma, pode-se inferir que a instalação da Escola Normal em Goiás foi um marco na história da educação e na formação de professores goianos. Mesmo não proporcionando os resultados desejados, essa ação representa uma tentativa do governo goiano em melhorar a problemática da precariedade do ensino primário que sempre estava presente nos debates políticos durante o período imperial.

\section{Referências}

Bretas, G. F. (1991). História da Instrução Pública em Goiás. Goiânia: CEGRAF-UFG. (Coleção Documentos Goianos, 21).

Canezin, M. T. e Loureiro, W. N. (1994). A escola normal em Goiás. Goiânia: CEGRAF-UFG. (Coleção Documentos Goianos, 28).

Gomes, J. A. S. (1851). Relatório do presidente da província de Goyaz. Goyaz: Typographia Provincial.

Goyaz. (1858). Collecção das Leis da Provincia de Goyaz. Goyaz: Typographia Provincial. 
Goyaz. (1882). Collecção das Leis da Provincia de Goyaz. Goyaz: Typographia Provincial.

Goyaz. (1884a). Instalação da Escola Normal. In: Correio Oficial de Goyaz, 26 abril 1884, p. 2-3, n. 17. Goyaz: Tipographia Provincial.

Goyaz. (1884b). Regulamento da Escola Normal de Goyaz: Ato n. 3.374, de 12 março de 1884. Goyaz: Typographia Provincial.

Goyaz. (1884c). Acta da primeira reunião da Congregação da Escola Normal em 7 de abril de 1884. In: Correio Oficial de Goyaz, 3 maio 1884, p. 3-4, n. 18. Goyaz: Tipographia Provincial.

Hahner, J. E. (2011). Escolas mistas, escolas normais: a coeducação e a feminização do magistério no século XIX. Revista Estudos Feministas, Florianópolis, v. 19, n. 2, p. 467-474.

Machado, E. O. (1850). Relatório do presidente da Província de Goyaz. Goyaz: Typographia Provincial.

Mascarenhas, J. A. (1839). Relatório do presidente da Província de Goyaz. Goyaz: Typographia Provincial.

Saviani, D. (2009). Formação de professores: aspectos históricos e teóricos do problema do contexto brasileiro. Revista Educação Brasileira, Brasília, DF, v. 14, n. 40, p. 143-155.

Silva, N. R. A. (1975). Tradição e renovação em Goiás. Goiânia: Oriente.

Tanuri, L. M. (2000). História da formação de professores. Revista Brasileira de História da Educação. Online, n. 14, maio/jun/jul/ago, p.61-88.

Villela, H. O. S. (2000). O mestre-escola e a professora. In: Lopes, E. M. T.; Faria Filho, L. M. e Veiga, C. G. (Org). 500 anos de educação no Brasil. 2. ed. Belo Horizonte: Autêntica, p. 95-134. 